\title{
ASSESSING THE IMPACT OF LUPUS NEPHRITIS IN A CHILDHOOD-ONSET SYSTEMIC LUPUS
} ERYTHEMATOSUS COHORT

Ana Paula Sakamoto (EPM-UNIFESP, São Paulo, SP, Brasil), Liana Soido Teixeira e Silva (EPM-UNIFESP, São Paulo, SP, Brasil), Ana Maria Loroño Terrazas (EPM-UNIFESP, São Paulo, SP, Brasil), Cláudio Arnaldo Len (EPM-UNIFESP, São Paulo, SP, Brasil), Clovis Artur Almeida da Silva (FMUSP, São Paulo, SP, Brasil), Maria Teresa Terreri (EPM-UNIFESP, São Paulo, SP, Brasil)

\section{BACKGROUND}

To determine the epidemiological profile and outcome of childhood-onset systemic lupus erythematosus (cSLE) patients with lupus nephritis (LN) undergoing medical treatment in a single tertiary Brazilian center.

\section{MATERIALS AND METHODS}

The cohort study included 202 cSLE patients followed from February 1987 to August 2016. All patients met the American College of Rheumatology (ACR) criteria and the Systemic Lupus Collaborating Clinics (SLICC) criteria for SLE, with disease onset before 18 years of age and current age up to 21 years. Presence of $L N, L N$ class, data on kidney function, including presence of end-stage renal disease (ESRD) were obtained from medical charts and renal biopsy.

\section{RESULTS}

We found that $146 / 202$ cSLE patients (72\%) developed LN, 76\% at disease onset. The majority were female $(88 \%)$ and $50 \%$ were Caucasian. Renal biopsy was performed in 37 patients at diagnosis and in 46 at follow-up with 38 (45\%) showing proliferative lesions (class III and IV according to the World Health Organization and International Society of Nephrology/Renal Pathology Society classification). Eighteen patients (12\%) developed ESRD: 13 patients underwent peritoneal dialysis and 10 hemodialysis (10 patients underwent both dialysis at follow-up). Two of the ESRD patients were submitted to renal transplantation. A total of 3 deaths occurred during the study period, but none of them was related to renal outcomes.

\section{CONCLUSION}

LN is the major cause of morbidity and mortality specially in CSLE, with progression to ESRD in approximately $10 \%$ of the cases. In most cases it was an early manifestation of the disease showing that, as expected, cSLE is associated with significant accrual damage in early stages of the disease and anytime at follow-up. 